\title{
FLAVONOIDS AS HYDROXYL RADICAL SCAVENGERS, IRON REDUCTANTS AND CHELATORS: IN VITRO ANTIOXIDANT ACTION
}

\author{
DAGMARA KURPIOS-PIEC ${ }^{1 *}$, MONIKA MAJEWSKA-WIERZBICKA ${ }^{1}$, HANNA CZECZOT ${ }^{1}$, \\ and MAŁGORZATA PODSIAD ${ }^{1}$
}

${ }^{1}$ Chair and Department of Biochemistry, Medical University of Warsaw, 02-097 Warszawa, Banacha 1, Poland

\begin{abstract}
Flavonoids are phytochemicals, which exhibit antioxidant potential due to their ability to donate a hydrogen atom and/or a single electron, and to interact with other antioxidants. The aim of this study was to evaluate the antioxidant potential of two subclasses of pure flavonoids: flavonols (quercetin, rhamnetin, isorhamnetin) and flavones (luteolin, apigenin) in vitro. Particularly, using spectrophotometric methods, we determined the ability of these flavonoids to scavenge hydroxyl radical, reduce ferric ions ( $\mathrm{Fe}$ (III)) and chelate ferrous ions ( $\mathrm{Fe}(\mathrm{II})$ ). Obtained results showed that tested flavonoids are good scavengers of hydroxyl radical and reductants ( $\mathrm{Fe}$ (III) $\rightarrow \mathrm{Fe}$ (II)) but relatively poor chelators of ferrous ions. Quercetin, which belongs to the group of flavonols was the most efficient antioxidant among tested flavonoids, while luteolin from the flavone group was the second one. We found that the number of hydroxyl groups and the presence of hydroxyl group at the $\mathrm{C} 3$ position of ring $\mathrm{C}$ corresponds with better hydroxyl radical scavenging activity and reduces the power of flavonoids. Catechol structure in the B ring was important for higher reducing power and chelating activity of flavonoids, but surprisingly it did not influence the hydroxyl radical scavenging activity of tested compounds. In contrary, the presence of the methoxy group in the structure of rhamnetin and isorhamnetin decreases their reducing power and chelating activity. Interestingly, the hydroxyl group at the $\mathrm{C} 5$ position of ring $\mathrm{A}$ was more important for the chelating activity of flavonoids than the hydroxyl group at the $\mathrm{C} 3$ position of ring C. Our research may enrich knowledge about the therapeutic potential of flavonoids as antioxidants.
\end{abstract}

Keywords: flavonoids, antioxidant potential, hydroxyl radical scavenger, iron reductant, iron chelator

Free radicals and Reactive Oxygen Species (ROS) such as superoxide anion radicals, hydroxyl radicals, hydrogen peroxide, singlet oxygen, and others are formed during normal cellular metabolism mainly as a byproduct of cellular respiration, or as a weapon used by phagocytes or other cell types to kill microorganisms (1). The production of ROS can be stimulated also by exogenous, environmental sources such as tobacco smoke, toxins, organic solvents, and pesticides (2). ROS may contribute to the pathogenesis of many diseases including chronic inflammation, neurodegeneration, and cancer $(3,4)$.

Physiologically, ROS are removed by antioxidant defense mechanisms including antioxidant enzymes (superoxide dismutase, catalase, glutathione peroxidases) and nonenzymatic antioxidants such as reduced glutathione (GSH), vitamins A, E, C, uric acid, and phytochemicals ( $\beta$-carotene, polyphenols, and others). Under pathological conditions, an imbalance between ROS production and antioxidant defense capacity can lead to oxidative stress. It can trigger damage of proteins, lipids, polyunsaturated fatty acids, nucleic acids, and carbohydrates, and in turn cause aging, cancer, and many other diseases e.g. heart disease, stroke, atherosclerosis, diabetes (4).

Antioxidant defense mechanisms can be reinforced by natural antioxidants found in food. One of the major group of naturally occurring antioxidants are flavonoids. They are very common in plants and plant products (fruits, vegetables, nuts, seeds, cereals, beverages) (5). The most commonly-consumed and widespread classes of flavonoids are flavonols and flavones. The representative of the first class is quercetin naturally occurring in vegetables: onion, lettuce, kale, broccoli, bean, buckwheat, potatoes, fruits: apples, peaches, and plant-derived beverages: tea and wine. Other flavonols, methylated derivatives of quercetin: rhamnetin and isorhamnetin are present mainly in onions, pears, and cloves. Flavones are frequently found in some vegetables, cereal grains

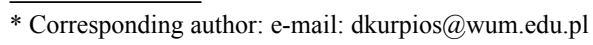


and herbs. The most common representatives of this group are apigenin and luteolin which occur mainly in celery, carrot, chicory, parsley, rosemary, and thyme (6-10).

The human body absorbs both the free flavonoids (aglycones) and those associated with sugars (flavonoid glycosides) (11). However, aglycones are much better absorbed than glycosidic forms $(12,13)$. The first step of metabolism of dietary flavonoid glycosides is their deglycosylation in the small intestine, where 1- $\beta$-glycosidase present in the brush border of the small intestine converts it into free aglycones (14). Absorbed aglycones are transported through the portal vein to the liver, where the second step of flavonoid transformation in the human body takes place. In the first phase of this process, which involves phase I detoxification enzymes (cytochromes P-450, especially CYP1A1, CYP1A2, CYP1B1, or CYP2E1), flavonoids are hydroxylated, methylated, and reduced (15). In the second phase of this process, which involves liver transferases, aglycones of flavonoids (90-95\% of absorbed flavonoids) are coupled at various rate with glucuronic or sulfuric acid and methylated, which increases their hydrophilicity and facilitates their excretion in urine or bile (16-18). Modifications of flavonoids and their metabolites during their digestion and absorption may change the activity of these compounds and affect the speed of their removal from the bloodstream. The efficiency of absorption of individual flavonoids by the body is influenced by both the type of flavonoids consumed, the physical and chemical properties of these compounds, as well as the presence and type of functional groups. Due to the metabolism of dietary glycosides and their fate in the gastrointestinal tract, it seems that only the flavonoid aglycones in the system show antioxidant activity in vivo.

Figure 1.

Structure of tested flavonoids.

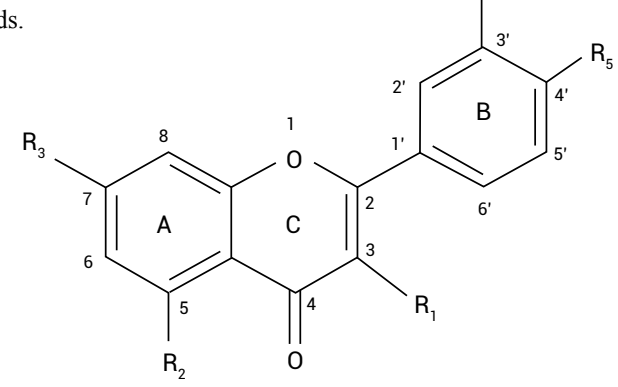

The mechanism of the antioxidant action of flavonoids is multifaceted and can be divided into direct and indirect $(7,19-22)$. The direct mechanism is based on the capture of ROS, which results in the disruption of free radical reactions. On the other hand, the indirect mechanism is based on chelation of transition metal ions $(\mathrm{Fe}, \mathrm{Cu})$; inhibition of the activity of enzymes involved in the production of ROS (e.g. xanthine oxidase, membrane NAD(P) $\mathrm{H}$ oxidase, myeloperoxidase, and lipoxygenases); protection and regeneration of other low molecular weight antioxidants (vitamins $\mathrm{C}$ and $\mathrm{E}$ ) and induction of the expression of enzymes involved in the detoxification of exogenous compounds (xenobiotics) (e.g. glutathione S-transferases or quinone oxidoreductases) (23-30). The antioxidant effects of flavonoids may be a combined result of their radical scavenging properties, interaction with enzyme activity, and other antioxidants (31).

It is known that the antioxidant properties of flavonoids depend on their chemical structure (Fig. 1). Many published articles indicate the following structural elements that determine flavonoid antioxidant activity: heterocyclic structure, the presence of hydroxyl groups (mainly in positions: $\mathrm{C} 5, \mathrm{C} 7$ of the A ring; C3', C4' of the $\mathrm{B}$ ring), double bond between $\mathrm{C} 2$ and $\mathrm{C} 3$ as well as the carbonyl group at the $\mathrm{C} 4$ position of the $\mathrm{C}$ ring (32-34). It is believed that the heterocyclic structure of the flavonoid ring allows the capture of free electrons, while the double bonds in the phenolic ring stabilize the structure and facilitate their movement. In turn, the hydroxyl groups in flavonoids are responsible for inactivating free radicals. By accepting an electron, flavonoids create relatively stable phenoxy radicals, thanks to which they can inhibit the chain reactions of lipid, protein, and DNA oxidation $(28,35)$. The available literature strongly emphasizes the role of the number of hydroxyl groups and their position in the antioxidant potential of polyphenolic compounds, including flavonoids (22, 36). In vitro and in vivo studies have shown that the methoxylation and glycosylation of flavonoid molecules in the $\mathrm{C} 3$ position significantly reduce the antioxidant activity of these compounds $(32,37,38)$. It has been observed that among flavonoids, flavanols have a stronger antioxidant effect than flavonols because their oxidation leads mainly to the formation of semiquinone radicals, which combine through nucleophilic addition to form oligomeric structures. Such a combination is possible thanks to

\begin{tabular}{|c|c|c|c|c|c|c|}
\hline Flavonoids & & $\mathrm{R}_{1}$ & $\mathrm{R}_{2}$ & $\mathrm{R}_{3}$ & $\mathrm{R}_{4}$ & $\mathrm{R}_{5}$ \\
\hline \multirow{3}{*}{ Flavonol } & Quercetin & $\mathrm{OH}$ & $\mathrm{OH}$ & $\mathrm{OH}$ & $\mathrm{OH}$ & $\mathrm{OH}$ \\
& Rhamnetin & $\mathrm{OH}$ & $\mathrm{OH}$ & $\mathrm{OCH}_{3}$ & $\mathrm{OH}$ & $\mathrm{OH}$ \\
& Isorhamnetin & $\mathrm{OH}$ & $\mathrm{OH}$ & $\mathrm{OH}$ & $\mathrm{OCH}_{3}$ & $\mathrm{OH}$ \\
\hline \multirow{2}{*}{ Flavone } & Luteolin & $\mathrm{H}$ & $\mathrm{OH}$ & $\mathrm{OH}$ & $\mathrm{OH}$ & $\mathrm{OH}$ \\
& Apigenin & $\mathrm{H}$ & $\mathrm{OH}$ & $\mathrm{OH}$ & $\mathrm{H}$ & $\mathrm{OH}$ \\
\hline
\end{tabular}


the catechol or pyrogallol group, which facilitates the scavenging of radicals (39). Literature data indicate that the chelating properties of flavonoids also depend on their chemical structure. The presence of hydroxyl groups in the flavonoid structure, especially in the B-ring, is essential for metal chelating. Moreover, the flavonoid-metal complexes show a greater ability to trap the superoxide radical than the flavonoids themselves $(40,41)$. Due to the lipophilic properties determined by the ring structure of flavonoids, it is possible to incorporate them into the lipid bilayer of the body's cell membranes. As a result, they can more effectively protect cells against the effects of the peroxidation of lipids and membrane proteins (42).

Antioxidant activity of flavonoids determines multiple ranges of their actions: antiallergic, antiinflammatory, antiviral, antiproliferative, anticarcinogenic, anti-hypertensive, and anti-thrombogenic (43-51). The variety of pharmacological activities of flavonoids, their importance in human health, and widespread availability make them appropriate candidates for therapeutic targets. In recent years, most of the research on the multidirectional effects of flavonoids, including antioxidant activity has focused mainly on plant extracts containing a mixture of these compounds (52-54). Despite such great interest in these polyphenols, there is little data on the in vitro and in vivo antioxidant activity of pure, single flavonoids, and mostly they refer to a single concentration (53-55).

Therefore, the aim of this study was to evaluate the antioxidant potential of selected flavonoids most common in the human diet, which belong to one of two classes: flavonols (quercetin, rhamnetin, isorhamnetin) or flavones (luteolin, apigenin). Particularly, using in vitro model, we determined the ability of these flavonoids to scavenge hydroxyl radical, reduce ferric ions (Fe (III)) and chelate ferrous ions (Fe (II)). Based on the obtained results we selected the flavonoid with the highest antioxidant potential.

\section{EXPERIMENTAL}

\section{Materials}

All tested flavonoids were purchased from Sigma-Aldrich. L-ascorbic acid, 6-hydroxy-2,5,7,8tetramethylchroman-2-carboxylic acid (Trolox) a synthetic analogue of vitamin E, butylated hydroxytoluene (BHT), dimethyl sulfoxide (DMSO), 3-(2-pyridyl)-5,6-bis(4-phenyl-sulfonic acid)-1,2,4triazine (ferrozine), ethylenediaminetetraacetic acid (EDTA), ammonium thiocyanate, 2-deoxy-2-ribose and ferric chloride, ferrous chloride were obtained also from Sigma-Aldrich. All other chemicals used were in analytical grade and obtained from $\mathrm{POCH}$ (Gliwice, Poland).

Quercetin, rhamnetin, isorhamnetin, luteolin, and apigenin were tested in the concentration range from 0.1 to $100 \mu \mathrm{g} / \mathrm{sample}$, which according to a different molecular weight of tested compounds correspond to concentration range respectively: $0.11-0.12 \mu \mathrm{M}$ to $105-123 \mu \mathrm{M}$ for hydroxyl radical scavenging activity, $0.12-0.14 \mu \mathrm{M}$ to $119-140 \mu \mathrm{M}$ for reducing power and ferrous ions chelating activity. Flavonoids were dissolved in DMSO. However, to determine their hydroxyl radical scavenging activity initial concentration of flavonoids was dissolved in the mixture of methanol and water $(1: 1)$, and then, further dilutions were made in water.

\section{Hydroxyl radical scavenging assay}

The hydroxyl radical scavenging activity of flavonoids was assayed using the Halliwell et al. (1987) method based on the determination of MDA, a degradation product of deoxyribose, by measurement of its condensation with TBA at $535 \mathrm{~nm}$ (55). The positive control was BHT dissolved in acetone at the same concentrations as tested flavonoids.

Hydroxyl radical scavenging activity of tested flavonoids was calculated using the following formula:

$$
\begin{gathered}
\text { Hydroxyl radical scavenging activity }(\%)= \\
=\left(\mathrm{A}_{\mathrm{BS}}-\mathrm{A}_{\mathrm{TS}}\right) / \mathrm{A}_{\mathrm{BS}} \times 100 \%
\end{gathered}
$$

$A_{B S}$ - the absorbance of blank sample

$\mathrm{A}_{\mathrm{TS}}$ - the absorbance of tested sample

\section{Reducing power assay}

The reducing power of flavonoids was determined by the method of Oyaizu (1986) (56). The absorbance was measured in a spectrophotometer at $700 \mathrm{~nm}$. As positive controls standard antioxidants were used: vitamin $\mathrm{C}$ dissolved in water, Trolox dissolved in DMSO and BHT dissolved in acetone at the same concentrations as tested compounds. The absorbance is a measurement of reducing power activity. The higher absorbance the higher reducing power.

\section{Ferrous ions (Fe(II)) chelating assay}

Ferrous ions chelating activity of tested compounds was estimated according to the Dinis et al. method (1994) (57). The positive control used in this method was EDTA and sodium citrate dissolved in water at the same concentrations as tested compounds. 
The absorbance of the mixture was measured spectrophotometrically at a wavelength of $562 \mathrm{~nm}$. Chelation of $\mathrm{Fe}$ (II) was calculated using the formula:

Chelation of Fe (II) $(\%)=\left(\mathrm{A}_{\mathrm{BS}}-\mathrm{A}_{\mathrm{TS}}\right) / \mathrm{A}_{\mathrm{BS}} \times 100 \%$

$A_{B S}$ - the absorbance of blank sample

$\mathrm{A}_{\mathrm{TS}}$ - the absorbance of tested sample

\section{Statistical analysis}

All data are the average of triplicate analyses from three separate experiments. The results were expressed as the mean values \pm standard deviation using Microsoft Office Excel program. Statistical analyses were performed using statistical package Statistica 13.3 program (StatSoft 13.3). Significant differences between means were determined by Student's t-test; P-values $\leq 0.05$ were regarded as significant.

\section{RESULTS}

For the comprehensive evaluation of the antioxidant potential of flavonols and flavones in a wide range of concentrations (0.1-100 $\mu \mathrm{g} / \mathrm{sample})$ many specific methods have been used in vitro. This allowed completing the characterization of the tested compounds as antioxidants. It has been shown that the antioxidant activity of flavonoids is based on both antioxidant mechanisms: direct action (inactivation of the hydroxyl radical and/or indirect action (chelation and reduction of transition metal ions).

\section{Hydroxyl radical scavenging activity of flavonoids}

Obtained results indicated that flavonoids are effective hydroxyl radical scavengers. Their activity is dose-dependent. Hydroxyl radical scavenging rate increases with their higher concentrations.

As seen in Figure 2A hydroxyl radical scavenging activity of quercetin, rhamnetin, isorhamnetin and positive control - BHT was high (even up to $70 \%$ ). The difference in activity between these compounds was slight. At low concentrations (0.1-0.5 $\mu \mathrm{g} / \mathrm{sample})$ all tested flavonols had similar activity range between 6-18\%. From the concentration $1 \mu \mathrm{g} /$ sample quercetin had the highest activity against hydroxyl radical (at the highest tested concentration reached $70 \%$ ). Rhamnetin and isorhamnetin had lower activity than quercetin and BHT $(\mathrm{P} \leq 0.05)$, but similar to each other (at the highest tested concentration reached $60 \%$ ).

Hydroxyl radical scavenging activity of tested flavones (apigenin, luteolin) at concentrations
0.1-0.5 $\mu \mathrm{g} /$ sample and $25-100 \mu \mathrm{g} / \mathrm{sample}$ was almost the same. Only at the concentration range 1-10 $\mu \mathrm{g} /$ sample apigenin was a stronger hydroxyl radical scavenger than luteolin $(\mathrm{P} \leq 0.05)$. Moreover, flavones at low concentrations (0.1-1 $\mu \mathrm{g} / \mathrm{sample})$ had similar hydroxyl radical scavenging activity as BHT and were weaker at high concentrations (25-100 $\mu \mathrm{g}$ / sample) $(\mathrm{P} \leq 0.05)$ (Fig. 2B).

Figure 3 illustrates comparison of hydroxyl radical scavenging activity of all tested flavonoids. This allowed to set them due to their antioxidant potential in the following order: quercetin $>$ luteolin $\approx$ rhamnetin $\approx$ isorhamnetin $\approx$ apigenin.

Our earlier, in vitro study, determining antioxidant activity of flavonoids (quercetin, rhamnetin, isorhamnetin, luteolin, apigenin) showed their ability to inactivate superoxide anion radical. All tested flavonoids exhibited effective antioxidant activity against this radical (58). Quercetin (especially at high concentrations) was the most effective scavenger of both superoxide anion radical and hydroxyl radical.

\section{Reducing power of flavonoids}

The antioxidant potential of flavonoids includes also their ability to interact with transition metal ions, especially iron. It relies on the reduction or chelation of the metal ions. The reducing power (the $\mathrm{Fe}$ (III) $\rightarrow \mathrm{Fe}$ (II) transformation) of all flavonoids (except apigenin) correlates well with concentrations. Their ability to Fe (III) reduction is dose-dependent.

All tested flavonoids (quercetin, rhamnetin, isorhamnetin, luteolin, apigenin) and positive controls (BHT, Trolox, ascorbic acid) at low concentrations $(0.1 \mu \mathrm{g} / \mathrm{sample}$ to $1 \mu \mathrm{g} / \mathrm{sample})$ demonstrated similar reducing power. At higher concentrations ( $2.5 \mu \mathrm{g} / \mathrm{sample}$ to $100 \mu \mathrm{g} / \mathrm{sample})$ ascorbic acid was the most effective reductant among all tested compounds $(\mathrm{P} \leq 0.05)$, apigenin was the weakest.

Among studied flavonols, quercetin demonstrated a powerful Fe (III) reducing ability (Fig. 4A). Its reducing power was even higher than these of positive controls: Trolox and ascorbic acid $(P \leq 0.05)$. The reducing ability of both methylated flavonols (rhamnetin, isorhamnetin) was lower than quercetin $(\mathrm{P} \leq 0.05)$. Rhamnetin has the same reducing capability as quercetin only at the highest concentration (100 $\mu \mathrm{g} / \mathrm{sample})$. Among tested flavones only luteolin had dose dependent reducing power (Fig. 4B). Apigenin had the lowest reducing capability among all tested flavonoids and its activity was independent on concentration. Luteolin was stronger reductant than Trolox and BHT but weaker than ascorbic acid. 
A.

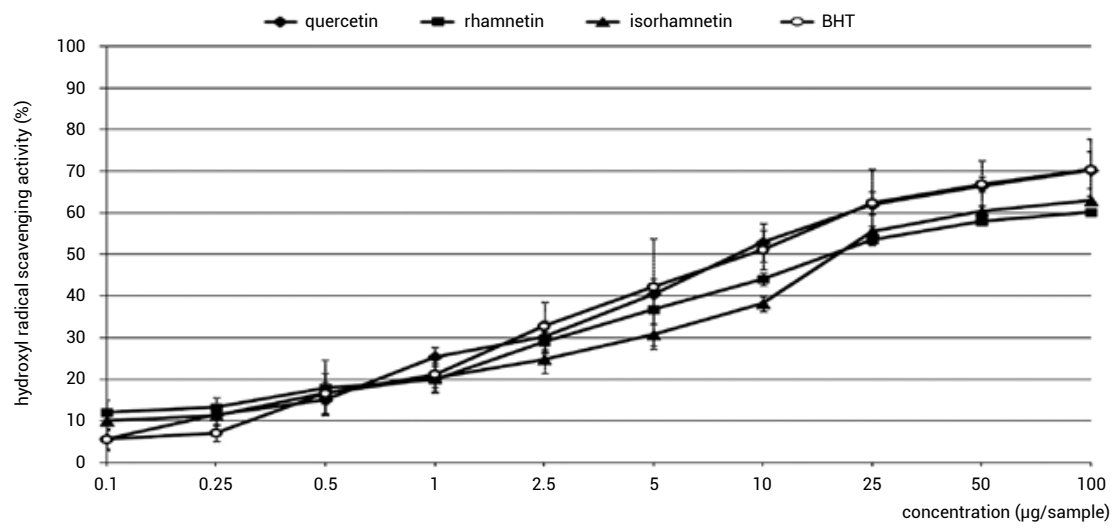

\begin{tabular}{|c|c|c|c|c|c|c|c|c|c|c|}
\hline $\begin{array}{ll}\text { Compound } & \text { Concentration ( } \mu \mathrm{g} / \mathrm{sample})\end{array}$ & 0.1 & 0.25 & 0.5 & 1 & 2.5 & 5 & 10 & 25 & 50 & 100 \\
\hline quercetin vs rhamnetin & * & & & * & & & * & * & * & * \\
\hline quercetin vs isorhamnetin & * & & & & * & * & * & * & * & * \\
\hline rhamnetin vs isorhamnetin & & & & & * & * & * & * & * & * \\
\hline quercetin vs BHT & & & & & & & & & & \\
\hline rhamnetin vs BHT & * & * & & & $*$ & * & $*$ & * & $*$ & $*$ \\
\hline isorhamnetin vs BHT & * & * & & & $*$ & * & * & * & * & * \\
\hline
\end{tabular}

B.

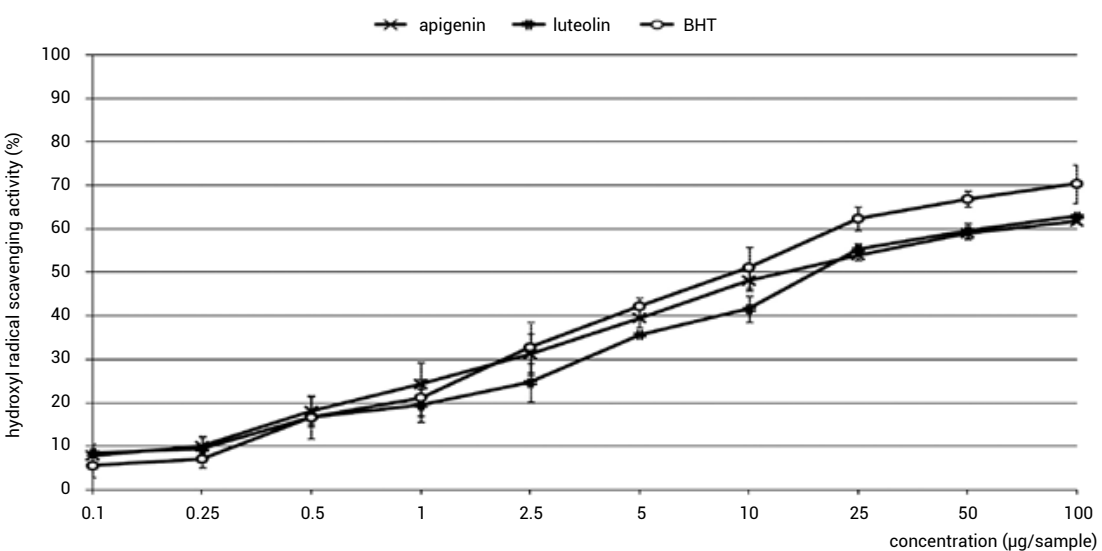

* significant differences beetwen means of tested compounds $P \leq 0.05$

\begin{tabular}{|l|c|c|c|c|c|c|c|c|c|c|}
\hline Compound & 0.1 & 0.25 & 0.5 & 1 & 2.5 & 5 & 10 & 25 & 50 & 100 \\
\hline apigenin vs luteolin & & & & & & $*$ & $*$ & & & $*$ \\
\hline apigenin vs BHT & & & & & & & & $*$ & $*$ & $*$ \\
\hline luteolin vs BHT & & & & & $*$ & $*$ & $*$ & $*$ & $*$ & $*$ \\
\hline
\end{tabular}

Figure 2. Hydroxyl radical scavenging activity of flavonols (A) and flavones (B) and the positive control, BHT. The data represent the percent of scavenged hydroxyl radical by tested flavonoids. The results are mean \pm SD of six measurements.

Figure 3. Profile of hydroxyl radical scavenging activity of tested flavonoids.

The results are present as a mean of ten measurements. $\square$ apigenin $=$ isorhamnetin $=$ rhamnetin $\equiv$ luteolin $=$ quercetin

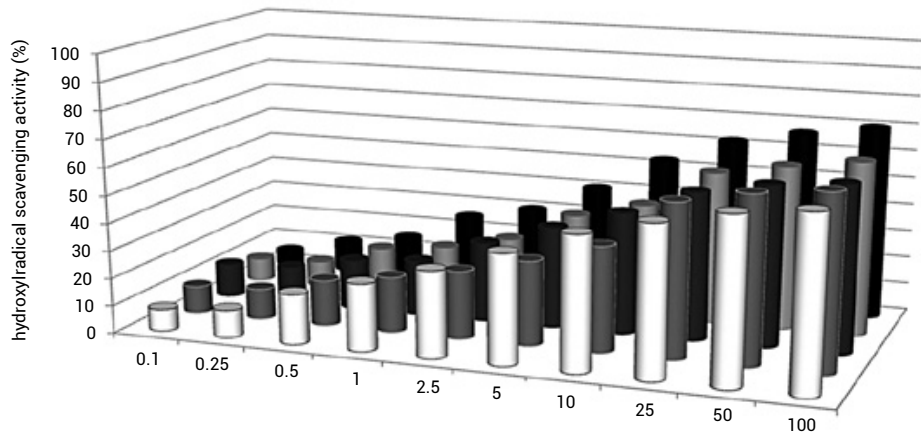

concentration ( $\mu \mathrm{g} / \mathrm{sample})$ 
A.

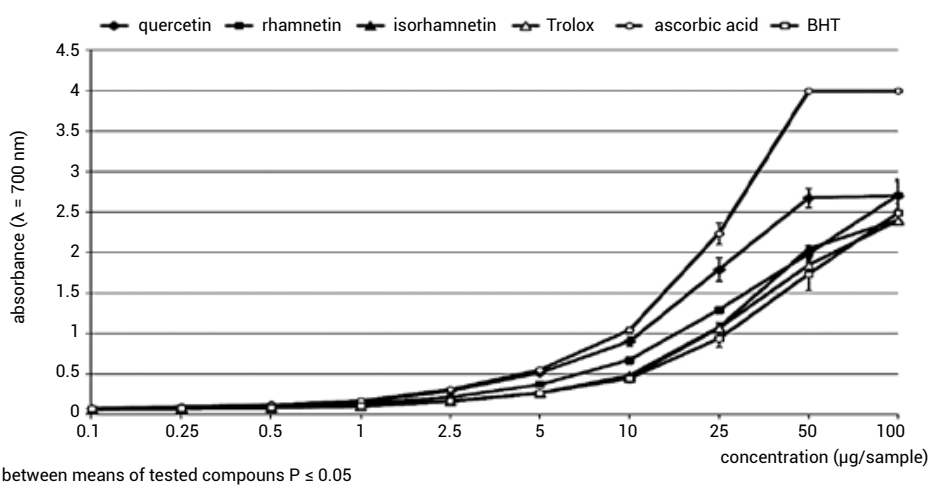

\begin{tabular}{|c|c|c|c|c|c|c|c|c|c|c|}
\hline \multicolumn{11}{|l|}{ cignificant difference haturen mancoftected compounc $P<005$} \\
\hline \begin{tabular}{lc|} 
Compound & Concentration $(\mu \mathrm{g} / \mathrm{sample})$ \\
\end{tabular} & 0.1 & 0.25 & 0.5 & 1 & 2.5 & 5 & 10 & 25 & 50 & 100 \\
\hline quercetin vs rhamnetin & * & * & * & * & * & * & * & * & * & \\
\hline quercetin vs isorhamnetin & * & * & $*$ & * & * & * & * & * & * & * \\
\hline rhamnetin vs isorhamnetin & * & * & $*$ & * & $*$ & * & $*$ & * & $*$ & * \\
\hline quercetin vs ascorbic acid & * & * & * & * & * & * & $*$ & * & $*$ & * \\
\hline quercetin vs Trolox & * & * & $*$ & * & * & * & $*$ & * & * & * \\
\hline rhamnetin vs ascorbic acid & & * & * & & * & & & & & * \\
\hline $\begin{array}{l}\text { Inamnetim V S Scorolic acla } \\
\text { rhamnetin vs Trolox }\end{array}$ & * & * & * & * & * & * & * & * & * & * \\
\hline isorhamnetin vs ascorbic acid & $*$ & * & * & * & * & * & * & * & * & * \\
\hline isorhamnetin vs Trolox & & & & & & & * & & * & \\
\hline Trolox vs ascorbic acid & * & * & * & * & * & * & * & * & * & * \\
\hline $\begin{array}{l}\text { Tolox vs ascorbic acla } \\
\text { quercetin vs BHT }\end{array}$ & $\star$ & * & ${ }_{*}^{*}$ & $*$ & * & * & * & * & * & * \\
\hline rhamnetin vs BHT & * & * & $*$ & * & * & * & * & $*$ & $*$ & $*$ \\
\hline isorhamnetin vs BHT & * & * & * & * & * & * & * & * & $*$ & * \\
\hline ascorbic acid vs BHT & $*$ & * & * & * & * & * & * & * & $*$ & $*$ \\
\hline Trolox acid vs BHT & $*$ & * & * & * & * & * & * & * & * & * \\
\hline
\end{tabular}

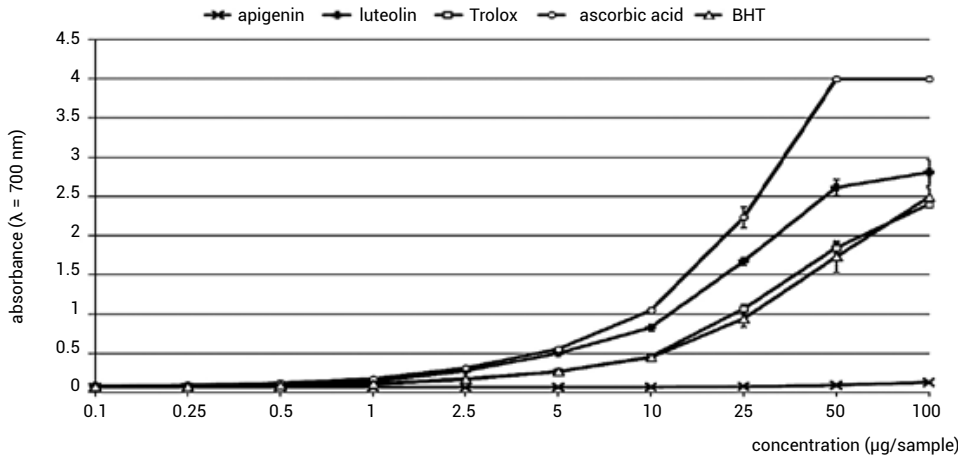

\begin{tabular}{|c|c|c|c|c|c|c|c|c|c|c|}
\hline \multicolumn{11}{|c|}{ significant differences between means of tested compouns $\mathrm{P} \leq 0.05$} \\
\hline Concentration ( $\mu \mathrm{g} / \mathrm{sample})$ & 0.1 & 0.25 & 0.5 & 1 & 2.5 & 5 & 10 & 25 & 50 & 100 \\
\hline apigenin vs luteolin & * & * & * & * & * & * & * & * & * & $*$ \\
\hline apigenin vs ascorbic acid & * & * & * & * & * & * & * & * & * & $*$ \\
\hline apigenin vs Trolox & * & * & * & * & * & * & * & * & * & * \\
\hline luteolin vs ascorbic acid & * & * & * & & & * & * & * & * & * \\
\hline luteolin vs Trolox & & * & * & $*$ & * & * & & * & * & \\
\hline Trolox vs ascorbic acid & * & * & $*$ & * & * & * & * & * & * & $*$ \\
\hline apigenin vs BHT & * & * & * & * & * & $*$ & * & * & * & * \\
\hline luteolin vs BHT & * & * & * & * & * & * & * & * & * & * \\
\hline ascorbic acid vs BHT & * & * & * & * & * & * & * & $*$ & * & $*$ \\
\hline Trolox vs BHT & * & * & * & * & * & * & * & * & * & * \\
\hline
\end{tabular}

Figure 4. The reducing power of tested flavonoids: flavonols (A), flavones (B) and the positive controls: Trolox, ascorbic acid and BHT. The absorbance $(\lambda=700 \mathrm{~nm})$ was plotted against concentration of tested compounds. Results are present as mean \pm SD of ten measurements.

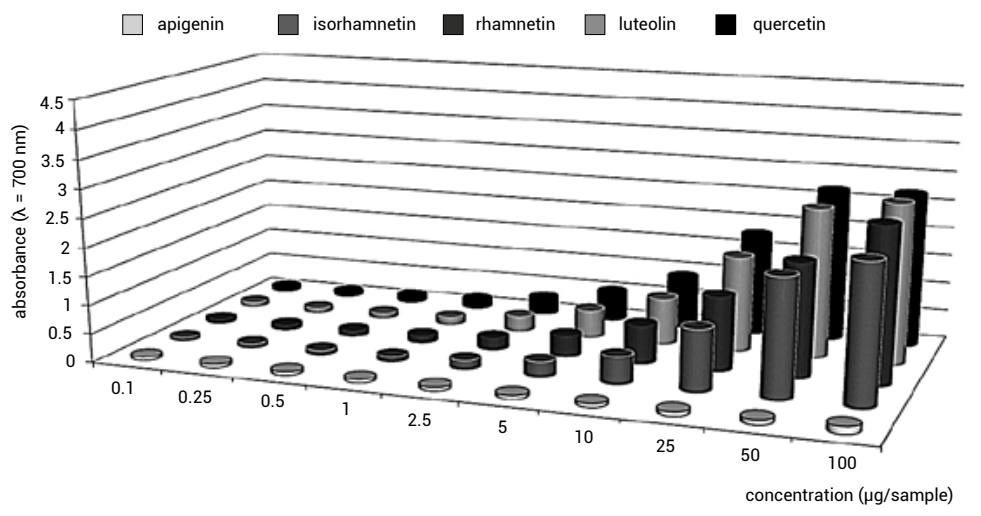

Figure 5. Profile of reducing power (Fe (III) $\rightarrow \mathrm{Fe}$ (II) of tested flavonoids The results are present as a mean of ten measurements. 
A.

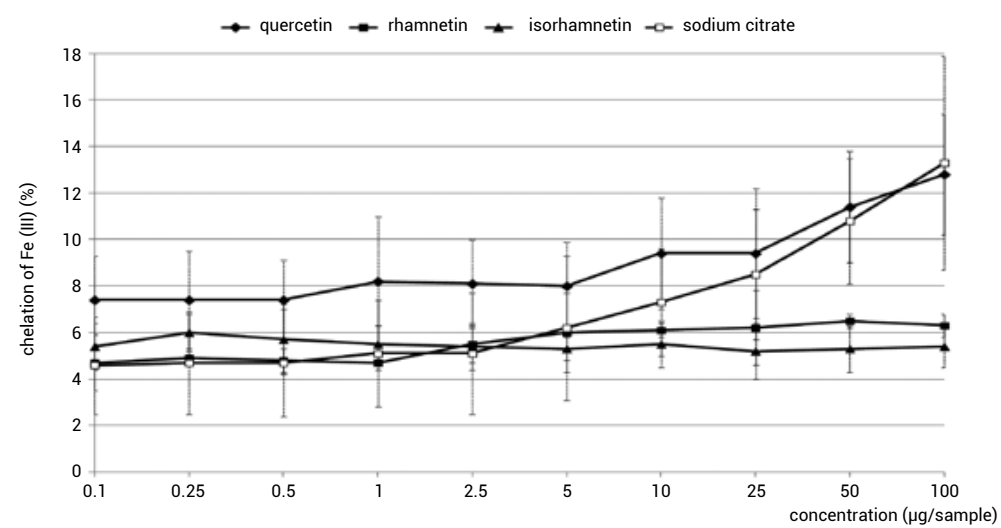

$A^{\prime}$.

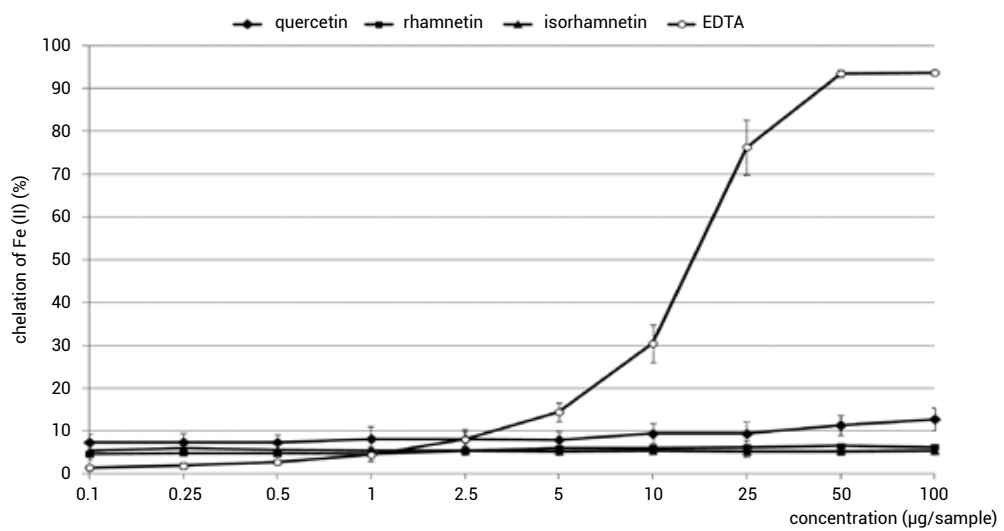

* significant differences between means of tested compounds $\mathrm{P} \leq 0.05$

\begin{tabular}{|c|c|c|c|c|c|c|c|c|c|c|}
\hline Compound Concentration ( $\mu \mathrm{g} / \mathrm{sample})$ & 0.1 & 0.25 & 0.5 & 1 & 2.5 & 5 & 10 & 25 & 50 & 100 \\
\hline quercetin vs rhamnetin & * & * & * & * & * & * & * & * & * & * \\
\hline quercetin vs isorhamnetin & * & * & * & * & * & * & * & * & * & * \\
\hline rhamnetin vs isorhamnetin & * & * & * & * & & * & * & * & * & * \\
\hline quercetin vs sodium citrate & * & * & * & * & * & * & * & & & \\
\hline quercetin vs EDTA & * & * & * & * & & * & * & $*$ & * & * \\
\hline rhamnetin vs sodium citrate & & & & & & & * & $*$ & * & * \\
\hline rhamnetin vs EDTA & * & * & * & & * & * & * & * & * & * \\
\hline isorhamnetin vs sodium citrate & & & & & & & * & * & * & * \\
\hline isorhamnetin vs EDTA & * & * & * & & * & * & * & * & * & * \\
\hline sodium citrate vs EDTA & * & * & * & & * & * & * & * & * & * \\
\hline
\end{tabular}

Figure 6 A. and A'. Ferrous ions chelation of tested flavonols and positive controls: sodium citrate (A) and EDTA (A'). The percentage of ferrous ions chelation was plotted against the concentration of tested compounds. Results are present as mean $\pm \mathrm{SD}$ of ten measurements.

The reducing power of all tested flavonoids decreased in the following order: quercetin $>$ luteolin $>$ rhamnetin $>$ isorhamnetin $>$ apigenin (Fig. 5). The observed differences in the reduction of Fe (III) to $\mathrm{Fe}$ (II) between the flavonoids were statistically significant $(\mathrm{P} \leq 0.05)$.

\section{Ferrous ions chelation of flavonoids}

Ferrous ion (Fe (II)) is the most powerful prooxidant among metal ions. It catalyzes the production of superoxide anion radicals, hydrogen peroxide, and hydroxyl radicals through the Haber-Weiss reaction. Fe (II) accelerates lipid oxidation by conversion of hydrogen peroxide to reactive free radicals through the Fenton reaction.

The ability of tested flavonoids to chelate ferrous ions is shown in Figure 6A, $\mathrm{A}^{\prime}$ and $6 \mathrm{~B}, \mathrm{~B}^{\prime}$.
Quercetin had the strongest chelating activity among all tested flavonoids $(\mathrm{P} \leq 0.05)$. At low concentrations (0.1-5 $\mu \mathrm{g} / \mathrm{sample})$ the percent of ferrous ions chelation is on the constant level and it slightly increases in higher concentrations. The chelating activity of quercetin is close to the sodium citrate (positive control) (Fig. 6A) but definitely lower than EDTA (the most effective chelator of tested compounds) $(\mathrm{P} \leq 0.05)$ (Fig. 6A'). The percent of ferrous ions chelation by rhamnetin and isorhamnetin was at the constant level (about 4.7-6.5\%). However, at low concentrations (0.1-1 $\mu \mathrm{g} / \mathrm{sample})$ isorhamnetin had high chelation activity, and conversely at higher concentrations (5-100 $\mu \mathrm{g} / \mathrm{sample})$ - rhamnetin. The differences were statistically significant $(\mathrm{P} \leq 0.05)$. Rhamnetin and isorhamnetin are less effective chelators Fe (II) than quercetin $(\mathrm{P} \leq 0.05)$. In higher concentrations 
B.

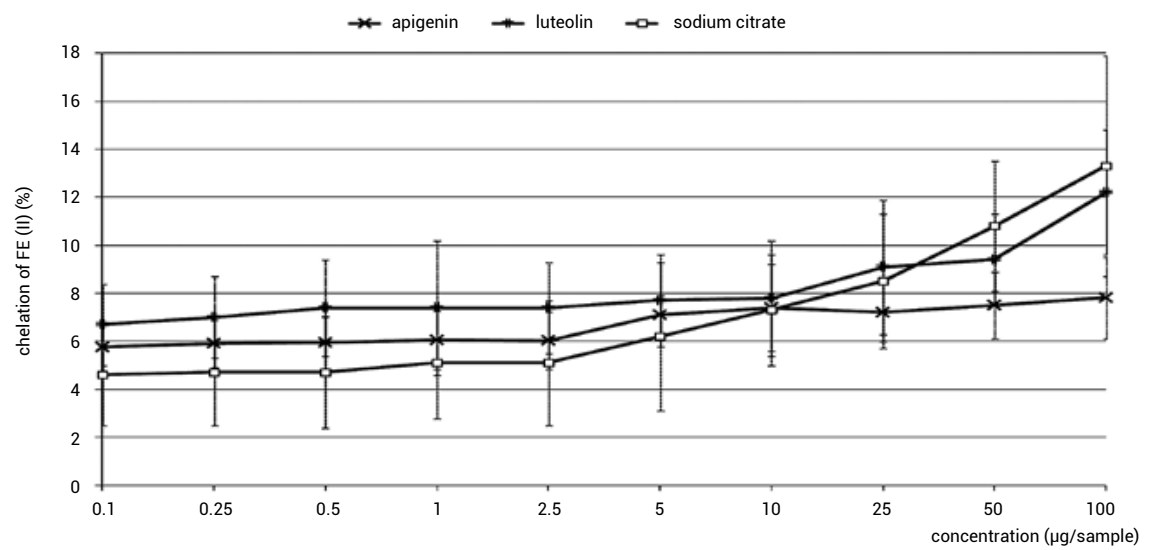

$B^{\prime}$.

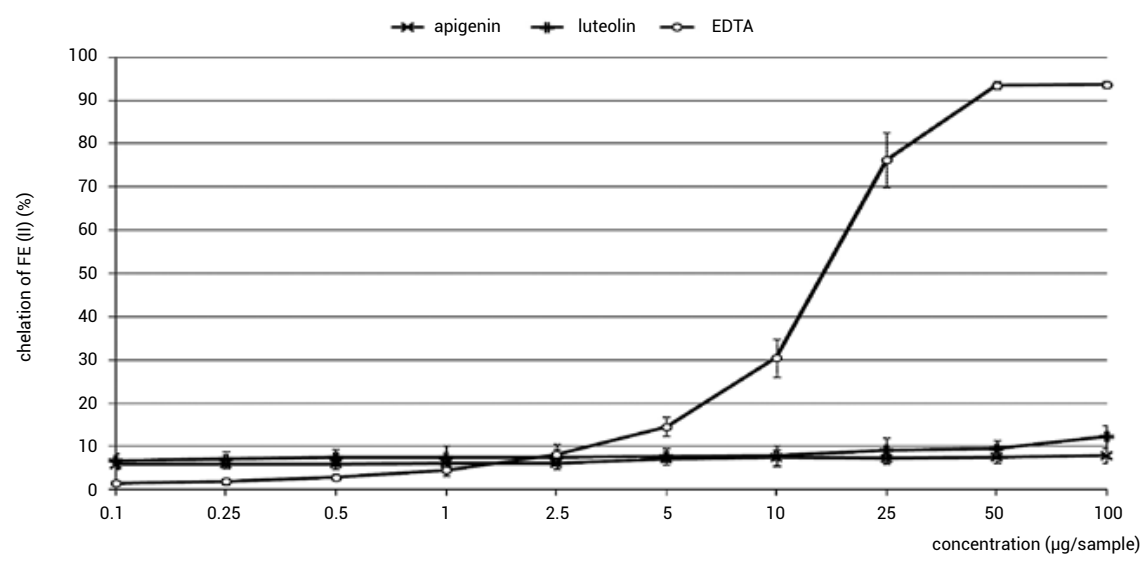

* significant differences between means of tested compounds $\mathrm{P} \leq 0.05$

\begin{tabular}{|c|c|c|c|c|c|c|c|c|c|c|}
\hline Concentration ( $\mu \mathrm{g} / \mathrm{sample})$ & 0.1 & 0.25 & 0.5 & 1 & 2.5 & 5 & 10 & 25 & 50 & 100 \\
\hline apigenin vs luteolin & & * & * & * & ${ }^{*}$ & & & ${ }^{*}$ & * & * \\
\hline apigenin vs sodium citrate & * & * & * & * & * & * & & * & * & * \\
\hline apigenin vs EDTA & * & * & * & * & * & * & * & * & * & * \\
\hline luteolin vs sodium citrate & * & * & * & * & * & * & * & * & * & * \\
\hline luteolin vs EDTA & * & * & * & * & & * & * & ${ }^{*}$ & ${ }^{*}$ & * \\
\hline sodium citrate vs EDTA & * & * & * & & * & * & * & * & ${ }^{*}$ & * \\
\hline
\end{tabular}

Figure 6 B. and B'. Ferrous ions chelation of tested flavones and positive controls: sodium citrate (B) and EDTA (B'). The percentage of ferrous ions chelation was plotted against concentration of tested compounds. Results are present as mean \pm SD of ten measurements.

(5-100 $\mu \mathrm{g} / \mathrm{sample})$ sodium citrate and EDTA are more effective Fe (II) ions chelators than rhamnetin and isorhamnetin (Fig. 6A and 6A').
Results obtained for tested flavones (luteolin and apigenin) indicate that luteolin was a more effective chelator than apigenin, but the difference

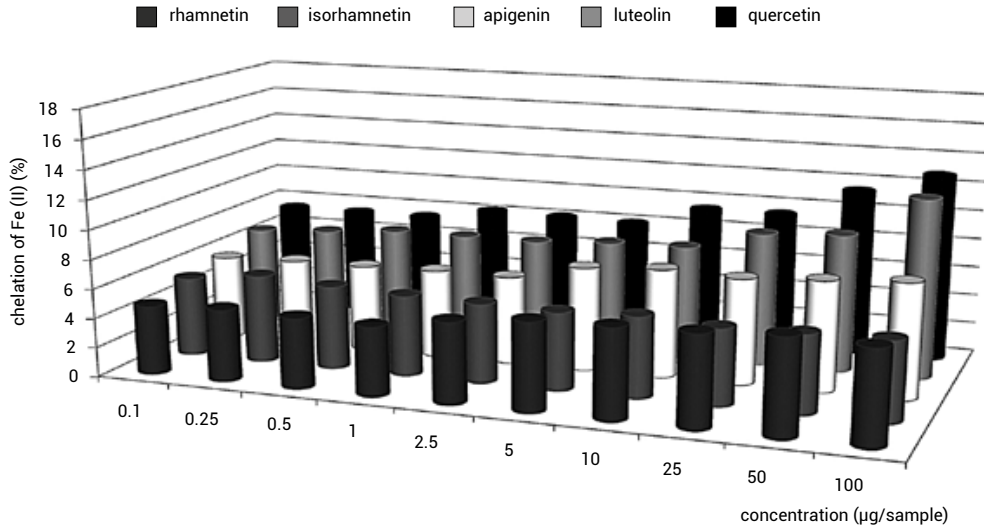

Figure 7. Profile of ferrous ions chelation of tested flavonoids. The results are present as a mean of ten measurements. 
between these flavones was small and range between $0.9-4.4 \%(\mathrm{P} \leq 0.05)$. The chelation activity of luteolin was similar to quercetin. Both tested flavones in the concentration range $0.1-5 \mu \mathrm{g} / \mathrm{sample}$ were more effective against $\mathrm{Fe}(\mathrm{II})$ ions than sodium citrate $(\mathrm{P} \leq 0.05)$ (Fig. 6B). From the concentration $10 \mu \mathrm{g} / \mathrm{sample}$ luteolin activity was similar to sodium citrate, apigenin weaker. Luteolin and apigenin (especially in high concentrations) are much weaker than EDTA (Fig. 6B').

All flavonoids chelate ferrous ions weakly. Their activity reaches only several percent.

Obtained results allow to set tested flavonoids according to their decreasing chelation activity in the following order: quercetin $\approx$ luteolin $>$ apigenin $>$ isorhamnetin $>$ rhamnetin (Fig. 7). Statistically significant differences were found for quercetin $v s$ apigenin, rhamnetin $v s$ luteolin, rhamnetin $v s$ apigenin, isorhamnetin $v s$ luteolin, isorhamnetin $v s$ apigenin $(\mathrm{P} \leq 0.05)$.

\section{DISCUSSION AND CONCLUSION}

The results obtained in our study indicated that the antioxidant potential of flavones and flavonols is determined by their structure. It seems that observed differences in antioxidant activity of tested flavonoids are not determined by the common elements present in their chemical structure: a double bond between $\mathrm{C} 2$ and $\mathrm{C} 3$, carbonyl group in the $\mathrm{C} 4$ position of $\mathrm{C}$ ring (Fig. 8). However, the ability to inactivate free radicals by quercetin and luteolin is influenced by the number of free hydroxyl groups (especially the presence of the $\mathrm{OH}$ group in the $\mathrm{C} 3$ position of the $\mathrm{C}$ ring) and the catechol group (two hydroxyl groups at C3' and C4' in the B ring). Quercetin had the highest number of hydroxyl groups (five) of tested compounds, luteolin, rhamnetin, and isorhamnetin - four free $\mathrm{OH}$ groups, while apigenin only - three. It was observed that the larger amount of free $\mathrm{OH}$ groups in the structure of the tested flavonoids, the greater increase of their antioxidant activity. In addition to quercetin and luteolin, rhamnetin also had a catechol group, but its antioxidant effect was weaker due to the presence of the methoxy group at the $\mathrm{C} 7$ position of the A ring. Isorhamnetin had an antioxidant effect similar to rhamnetin, but definitely weaker than that of quercetin and luteolin, which may be due to the lack of a catechol group and the presence of a methoxy group in the C3' position of the B ring. In our research, the weakest ability to inactivate free radicals was shown by apigenin, which is probably associated with the lowest amount of free $\mathrm{OH}$ groups and no catechol group.

\section{Hydroxyl radical scavenging activity}

Hydroxyl radical, generated in Fenton reaction from superoxide radical and hydrogen peroxide in the presence of transition metal ions $(\mathrm{Fe}, \mathrm{Cu})$ is the most reactive among ROS. Because of the highest single-electron reduction potential hydroxyl radical can react with all of the macromolecules in the cells: lipids, proteins, or DNA (59). Therefore the aim of this study was to determine the ability of flavonoids to inactivate hydroxyl radicals in vitro.

All tested flavonoids showed antioxidant activity against the generated hydroxyl radical in vitro. However, their potential was different and concentration-dependent. Quercetin had the strongest antioxidant effect against the hydroxyl radical, followed by luteolin, and the weakest - apigenin. The antioxidant potential of rhamnetin and isorhamnetin towards the hydroxyl radical was similar but lower than that of quercetin and luteolin.

On the basis of literature data and obtained results it can be assumed that the differences in hydroxyl radical scavenging activity of tested flavonoids are likely due to their different chemical structure. Generally, it seems that more free hydroxyl groups in flavonoid molecules correspond with a greater scavenging effect (60). Quercetin, which has five hydroxyl groups, was the most effective in scavenging hydroxyl radical activity. Also, the position of hydroxyl groups in flavonoids' basic structure is probably crucial for their antioxidant activity. Literature data have shown that during the inactivation of the superoxide radical, hydroxyl radical, peroxyl radical, and peroxynitrite very important are
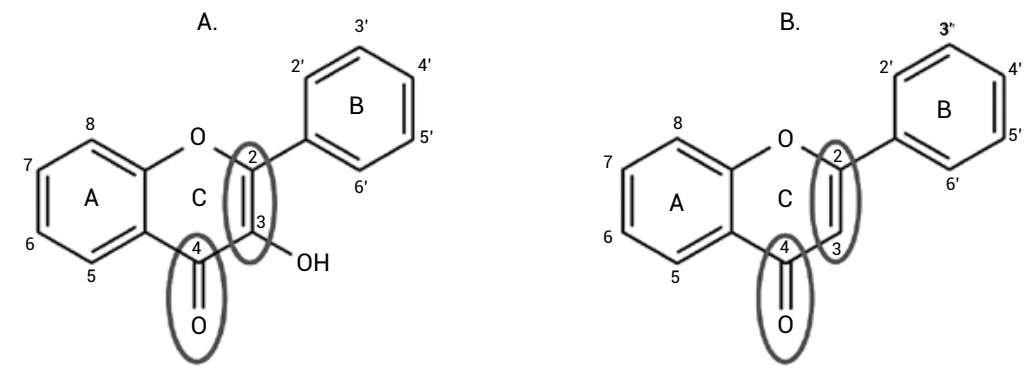

Figure 8. Common elements present in the structure of flavonoles (A) and flavones (B). 
$\mathrm{OH}$ groups located in ring $\mathrm{B}$ of flavonoids, which donate the hydrogen and electrons. The presence of $\mathrm{OH}$ groups in ring $\mathrm{A}$ has a much smaller effect on the antioxidant activity of flavonoids compared to their presence in ring $\mathrm{B}$. The antioxidant activity of flavonoids can be increased if they have both an $\mathrm{OH}$ group at the $\mathrm{C}^{2}$ ' position in ring $\mathrm{B}$ and an $\mathrm{OH}$ group at $\mathrm{C} 5$ and $\mathrm{C} 7$ position in ring $\mathrm{A}(30,32,35)$. According to Burda and Oleszek radical scavenging activity of flavonoids is determined mainly by the presence of hydroxyl group at the $\mathrm{C} 3$ position of ring $\mathrm{C}$ as it is in flavonols structure (22). It seems that this group positively influences the stabilization of the phenoxy radical. Flavonoids with free $\mathrm{OH}$ group at $\mathrm{C} 3$ position have a flat spatial structure, while those without it have a slightly twisted structure. The $\mathrm{OH}$ group at the $\mathrm{C} 3$ position of the ring $\mathrm{C}$ creates an internal hydrogen bond with $\mathrm{H}$ atom at $\mathrm{C} 2$ ' or $\mathrm{C} 6$ ' positions of the ring $\mathrm{B}$ what causes the rings of the flavonoid structure to be in the same plane. According to Arora et al. lack of $\mathrm{OH}$ group at the $\mathrm{C} 3$ position of the ring $\mathrm{C}$ (as in luteolin and apigenin) prevents from formating the hydrogen bond what causes a slight twisting of the ring $\mathrm{B}$, what results in a deterioration of electron delocalization and a decrease in the antioxidant activity of flavonoids (37). During the inactivation of free radicals, the flat spatial structure of flavonoid allows the attachment and movement of an electron, which increases the stability of the formed phenoxy radical $(22,61)$. Our results also confirm this thesis, quercetin (flavonol, which has an $\mathrm{OH}$ group at C3) had higher scavenging radical activity than luteolin (flavone, which is free of this group).

The study conducted by Chen et al. on the influence of the chemical structure of flavonoids on their ability to scavenge hydroxyl radical showed that it depends primarily on the number and location of free hydroxyl groups in their molecule. According to the authors, the most important in the inactivation of the hydroxyl radical are hydroxyl groups in the ring $\mathrm{A}$ of the flavonoids and the presence of $\mathrm{OH}$ group at $\mathrm{C} 3$ position in the ring $\mathrm{C}$. Location of $\mathrm{OH}$ groups in the ortho position in ring A increases the antioxidant activity compared to the meta position (33). The results obtained in this study are consistent with Chen et al. observations. We have shown that the greatest capacity to scavenge hydroxyl radical has quercetin. Rhamnetin and isorhamnetin, which are methylated derivatives of quercetin, have a similar ability for scavenging hydroxyl radical, but less than quercetin. These results and literature data indicate that methoxy groups irrespective of their position do not have a decisive influence on the antioxidant potential of flavonoids against hydroxyl radical (32). In vitro and in vivo tests showed a relationship between the presence of a methoxy group in the flavonoid molecule and lowering their antioxidant activity, especially when the methoxy group is added to the ring B. Suppression of antioxidant activity by methoxy groups is probably a consequence of the altered spin-distribution and stabilization of the flavonoid phenoxy radical (37).

There are many studies indicating the important role of a catechol structure (two hydroxyl groups in an ortho-position of ring B) in hydroxyl radical scavenging activity of flavonoids. The removal of one hydroxyl group from this structure significantly decreases this activity. It is believed that catechol moiety forms a relatively stable radical in a direct reaction between flavonoid and hydroxyl radical (28, 32). But our results show that this structure is not the most important in hydroxyl radical scavenging activity. Apigenin, which does not have a catechol structure has similar activity as luteolin, which has this structure.

\section{Reducing power}

The iron present in the human body (hemoglobin, myoglobin, enzymes e.g.: cytochromes, transferrin, ferritin, and others) is involved in many biochemical processes. The main form of iron in food is Fe (III). In the intestine, in the presence of various components of the food (e.g. flavonoids, ascorbic acid) it is reduced to a very soluble, easily accessible, and absorbed Fe (II) ion form. It should be remembered that Fe (III) in biological systems is the less active form, but the Fe (II) in excess may be toxic because it takes part in free radical reactions with reactive oxygen species as products (e.g. hydroxyl radical) (62).

Literature data indicate that flavonoids can react with iron ions. Thanks to their antioxidant activity they can reduce or chelate them (63). The reducing capacity of tested flavonoids may serve as a significant indicator of their antioxidant potential. Compounds with ferric ions (Fe (III)) reducing ability and also electron donor properties may play a crucial role in terminating the free radicals initiated chain reactions, which may otherwise be very damaging (64).

Obtained results demonstrate that quercetin was the strongest reductant of ferric ions among all tested flavonoids. Also, luteolin had similar high reducing power. Methylated flavonols (rhamnetin and isorhamnetin) showed similar activity against ferric ions, however lower than quercetin and luteolin. Apigenin was the weakest tested flavonoid. The reducing power of tested flavonoids was concentration-dependent. 
Our results indicate that the reducing power of tested flavonoids depends on their chemical structure. Besides the common elements of structure (double bond between $\mathrm{C} 2-\mathrm{C} 3$ and carbonyl group of $\mathrm{C}$ ring) it depends on the number of hydroxyl groups (especially hydroxyl group at the $\mathrm{C} 3$ position of $\mathrm{C}$ ring), catechol structure of $\mathrm{B}$ ring, and methoxy groups (65).

The high reducing power of quercetin is probably determined by the largest number of $\mathrm{OH}$ groups (five), the presence of $\mathrm{OH}$ group at position $\mathrm{C} 3$ of the $\mathrm{C}$ ring, and the catechol structure of the $\mathrm{B}$ ring. Luteolin due to the presence of four $\mathrm{OH}$ groups and catechol structure in B ring also showed powerful Fe (III) reducing ability but weaker than quercetin (smaller number of $\mathrm{OH}$ groups and lack $\mathrm{OH}$ group at the $\mathrm{C} 3$ position of $\mathrm{C}$ ring). The low reducing power of rhamnetin and isorhamnetin may be due to the presence of methoxy group at the $\mathrm{C} 7$ position of A ring (rhamnetin) or at C3' position of $\mathrm{B}$ ring (isorhamnetin). Consequently, apigenin having the least number of hydroxyl groups (only three), lacking $\mathrm{OH}$ group at the $\mathrm{C} 3$ position of $\mathrm{C}$ ring, and catechol structure of $\mathrm{B}$ ring was the weakest reductant of ferric ions. These observations are consistent with studies of other authors (65-67). Fernandez et al. and Firuzi et al. showed, the effect of the number of $\mathrm{OH}$ groups, their location, and the special role of the $\mathrm{OH}$ group at the $\mathrm{C} 3$ position in the ring $\mathrm{C}$ of the flavonoid structure on their reducing properties of $\mathrm{Fe}$ (III) ions $(65,66)$. Also, Pulido et al., using a different method for determining the reducing properties of iron (III) ions, observed that the number of $\mathrm{OH}$ groups is important in the reduction of Fe (III) by flavonoids. The more of them, the stronger the reducing properties of these compounds (67).

\section{Ferrous ions chelation by flavonoids}

Iron present in our diet is converted into free ferric (Fe (III)) and ferrous (Fe (II)) ions. Both forms of iron are absorbed in the intestine, but $\mathrm{Fe}$ (II) is much easier. During digestion, the interaction between iron ions and compounds of plant origin e.g. complexion/chelation can occur. Free ions of iron, present in biological systems, especially $\mathrm{Fe}$ (II) are involved in the Fenton reaction, in which is produced the most active of all radicals - hydroxyl radical. Its formation in the body is closely related to the concentration of ferrous ions in the cells. The capacity of flavonoids to chelate Fe (II) effectively reduces the concentration of these ions and thereby their ability to oxidize other substances and the amount of hydroxyl radical formed in Fenton's reaction $(62,68)$. Ferrous ions via hydroxyl radical

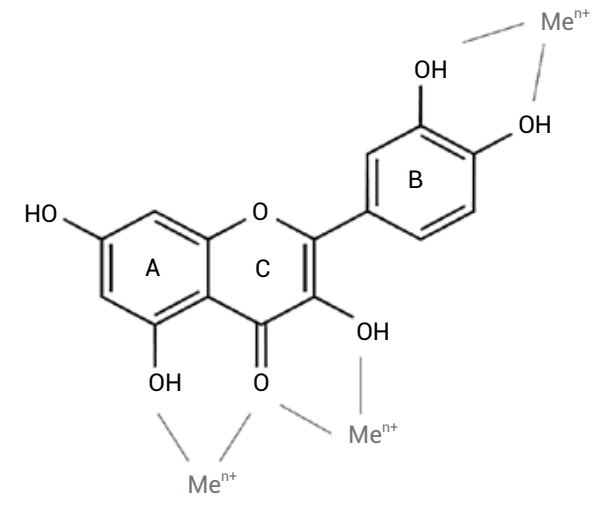

Figure 9. Chemical structure of flavonoid with marked most common sites involved in chelation of transition metals (41).

are responsible for oxygen free radicals and reactive oxygen species production which initiate lipid peroxidation of cell membranes. Therefore, the chelation of free ions Fe (II) can effectively block the oxidation of lipids in cell membranes. Additionally, the formation of flavonoid-iron chelates does not cause the inactivation of polyphenols. Flavonoidiron complexes retain the ability to scavenge ROS, particularly superoxide anion $(41,69)$.

Obtained results indicated that tested flavonoids are not effective chelators of ferrous ions (Fe (II)). Their activity was not dependent on concentration. Quercetin had the highest chelating activity among tested flavonols, and luteolin among flavones. The chelating activities of other tested flavonoids were similar.

Literature data suggest that the preferable sites of ferrous ions chelation in flavonoids' structure are: between the $\mathrm{C} 5-\mathrm{OH}$ and $\mathrm{C} 4-\mathrm{C}=\mathrm{O}$ group, between $\mathrm{C} 3-\mathrm{OH}$ and $\mathrm{C} 4-\mathrm{C}=\mathrm{O}$ group, and between the C3',C4'$\mathrm{diOH}$ of B ring (catechol group) (Fig. 9) (70). Our results confirmed these data partially. Quercetin and luteolin which have a hydroxyl group at the $\mathrm{C} 5$ position of ring $\mathrm{A}$, the carbonyl group at the $\mathrm{C} 4$ position of ring $\mathrm{C}$, and the catechol moiety of the ring $\mathrm{B}$ were the strongest chelators of ferrous ions among tested flavonoids. Higher chelation activity demonstrated by luteolin compared with apigenin confirm the importance of catechol moiety in the ring B in this activity. Based on our results, it seems that the hydroxyl group at the $\mathrm{C} 3$ position of the ring $\mathrm{C}$ is not so significant in the chelation of ferrous ions. Quercetin, with this group and luteolin without it, have similar chelating activity. This result indicated that a more important structure is the hydroxyl group at the $\mathrm{C} 5$ position of ring $\mathrm{A}$ than a hydroxyl group at the $\mathrm{C} 3$ position of the ring C. Fernandez et al. also considered that hydroxyl group at the $\mathrm{C} 5$ position of ring A with the 4-oxo 
group in the ring $\mathrm{C}$ play the most important role in chelation of Fe (II) by flavonoids (66).

The mentioned above preferable positions for chelation of ferrous ions by flavonoids depend on $\mathrm{pH}$ conditions. Under neutral conditions catechol group of B ring plays a major role in Fe (II) chelation, under acidic condition - the hydroxyl group at the $\mathrm{C} 5$ position of ring $\mathrm{A}$ and the carbonyl group at the $\mathrm{C} 4$ position of ring $\mathrm{C}$. Free $6-\mathrm{OH}$ and $7-\mathrm{OH}$ groups may be alternative chelating sites in flavonoids' structure (71).

In our research was also shown that methylated derivatives of flavonoids (rhamnetin and isorhamnetin) had ferrous chelation activity. It is consistent with Hudson and Lewis studies on copper ion chelation activity of these methylated flavonoids (72). Additionally, the differences in the chelation activity between quercetin and its methylated derivatives observed in our study indicate that the presence of methoxy group decreases their chelation ability despite the presence of potential chelation sites.

In conclusion, the results of this study have shown the antioxidant potential of all tested flavonoids (quercetin, rhamnetin, isorhamnetin, luteolin, apigenin). Applied assays were useful for the determination of these compounds' abilities to scavenge hydroxyl radical, reduce ferric ions (Fe (III)), and chelate ferrous ions (Fe (II)).

Our research demonstrated that tested flavonoids are good scavengers of hydroxyl radical and reductants (Fe (III) $\rightarrow \mathrm{Fe}$ (II)) but relatively poor chelators of ferrous ions. Quercetin, which belongs to the group of flavonols was the most efficient antioxidant among tested flavonoids, while luteolin from the flavone group was the second one. The findings obtained in the study and literature data clearly indicate that the differences in the antioxidant potential of the studied flavonoids resulted from their different chemical structure.

Apart from the common elements of the chemical structure of flavonoids (the double bond between C2-C3 and the carbonyl group of C-ring), their antioxidant potential seems to be determined by the number of hydroxyl groups (especially the hydroxyl group in the $\mathrm{C} 3$ position of the $\mathrm{C}$ ring), the catechol structure of the B-ring or the presence of methoxy groups. The greater amount of free $\mathrm{OH}$ groups and the presence of a catechol group in the structure of quercetin and luteolin increased their antioxidant activity, while the presence of methoxy groups decreased the antioxidant activity of rhamnetin and isorhamnetin. The lowest antioxidant potential of apigenin was probably due to the lowest number of
$\mathrm{OH}$ groups and the lack of a catechol group in its chemical structure.

Proven in this study the antioxidant potential of flavonols and flavones against free radicals and their ability to chelate transition metal ions demonstrate the specific role of these compounds in reducing oxidative stress in our organism. This is particularly important in the gastrointestinal tract, where commonly present in the daily diet flavonoids not only scavenge already generated reactive oxygen species but prevent their formation via the inhibition of the Fenton reaction. Maintenance of intestinal redox homeostasis is especially beneficial when the diet is rich in polyunsaturated fatty acids that are essential for our body. Flavonoids protect against peroxidation of fatty acids, and in consequence toxicity of lipid oxidation products, e.g. malondialdehyde, 4-hydroxynonenal. These compounds can exert negative effects within the colon or after absorption cause systemic adverse effects, including the induction of neoplastic changes. The obtained results confirm the importance of flavonoids as dietary antioxidants in the protection of the body's cells against the effects of oxidative stress and are part of the search for the effective natural antioxidants..

\section{Conflicts of interest}

The authors declare that there are no conflicts of interest.

\section{REFERENCES}

1. Kumar S.: Adv. Appl. Sci. Res. 2, (2011).

2. Phaniendra A., Jestadi D.B., Periyasamy L.: Indian J. Clin. Biochem. 30, 11 (2015).

3. Alfadda A.A., Sallam R.M.: J. Biomed. Biotechnol. 2012, 64 (2012).

4. Birben E., Sahiner U.M., Sackesen C., Erzurum S., Kalayci O.: World Allergy Organ. J. 5, 9 (2012).

5. Pandey K.B., Rizvi S.I.: Oxid. Med. Cell. Longev. 2, 270 (2009).

6. Panche A.N., Diwan A.D., Chandra S.R.: J. Nutr. Sci. 5, 64 pages (2016).

7. Wiczkowski W., Piskuła M.K.: Pol. J. Food Nutr. Sci. 54, 101 (2004).

8. Shahidi F., Ambigaipalan P.: Journal of Functional Foods 18, 757 (2015).

9. Majewska M., Skrzycki M., Podsiad M., Czeczot H.: Acta Pol. Pharm. 68, 611 (2011).

10. Xu D.P., Li Y., Meng X., Zhou T., Zhou Y., et al.: Int. J. Mol. Sci. 18, 93 pages (2017). 
11. Hollman P.C., de Vries J.H., van Leeuwen S.D., Mengelers M.J., Katan M.B.: Am. J. Clin. Nutr. 62, 1276 (1995).

12. Piskula M.K., Terao J.: J. Nutr. 128, 1172 (1998).

13. Piskula M.K., Terao J.: J. Agric. Food Chem. 46, 4313 (1998).

14. Day A.J., DuPont M.S., Ridley S., Rhodes M., Rhodes M.J., et al.: FEBS Lett. 436, 71 (1998).

15. Lee M.J., Maliakal P., Chen L., Meng X., Bondoc F.Y., et al.: Cancer Epidemiol. Biomarkers Prev. 11, 1025 (2002).

16. Clifford M.N.: Planta Med. 70, 1103 (2004).

17. Kuhnle G., Spencer J.P., Schroeter H., Shenoy B., Debnam E.S., et al.: Biochem. Biophys. Res. Commun. 277, 507 (2000).

18. Hollman P.C., Katan M.B.: Food Chem. Toxicol. 37, 937 (1999).

19. Prochazkova D., Bousova I., Wilhelmova N.: Fitoterapia 82, 513 (2011).

20. Czeczot H.: Pol. J. Food Nutr. Sci. 50, 3 (2000).

21. Nijveldt R.J., van Nood E., van Hoorn D.E., Boelens P.G., van Norren K., et al.: Am. J. Clin. Nutr. 74, 418 (2001).

22. Burda S., Oleszek W.: J. Agric. Food Chem. 49, 2774 (2001).

23. Cherrak S.A., Mokhtari-Soulimane N., Berroukeche F., Bensenane B., Cherbonnel A. et al.: PLoS One 11, e0165575 (2016).

24. Banjarnahor S., Artanti N.: Med. J. Indones. 23, 239 (2015).

25. Malešev D., Kuntić V.: J. Serbian Chem. Soc. 72, 921 (2007).

26. Shashirekha M.N., Mallikarjuna S.E., Rajarathnam S.: Crit. Rev. Food Sci. Nutr. 55, 1324 (2015).

27. Wolfe K.L., Liu R.H.: J. Agric. Food Chem. 56, 8404 (2008).

28. Shiba Y., Kinoshita T., Chuman H., Taketani Y., Takeda E., et al.: Chem. Res. Toxicol. 21, 1600 (2008).

29. Myhrstad M.C., Carlsen H., Dahl L.I., Ebihara K., Glemmestad L., et al.: Nutr. Cancer 54, 94 (2006).

30. Sanz M.J., Ferrandiz M.L., Cejudo M., Terencio M.C., Gil B., et al.: Xenobiotica 24, 689 (1994).

31. Kumar S., Pandey A.K.: ScientificWorldJournal 2013, 66 pages (2013).

32. Rice-Evans C.A., Miller N.J., Paganga G.: Free Radic. Biol. Med. 20, 933 (1996).

33. Chen J.W., Zhu Z.Q., Hu T.X., Zhu D.Y.: Acta Pharmacol. Sin. 23, 667 (2002).

34. Bors W., Heller W., Michel C., Saran M.: Methods Enzymol. 186, 343 (1990).
35. Cao G., Sofic E., Prior R.L.: Free Radic. Biol. Med. 22, 749 (1997).

36. Chang W.T., Shao Z.H., Yin J.J., Mehendale S., Wang C.Z., et al.: Eur. J. Pharmacol. 566, 58 (2007).

37. Arora A., Nair M.G., Strasburg G.M.: Free Radic. Biol. Med. 24, 1355 (1998).

38. Nichenametla S.N., Taruscio T.G., Barney D.L., Exon J.H.: Crit. Rev. Food Sci. Nutr. 46, 161 (2006).

39. Bors W., Michel C., Stettmaier K.: Arch. Biochem. Biophys. 374, 347 (2000).

40. Yoneda S., Nakatsubo F.: J. Wood Chem. Technol. 18, 193 (1998).

41. Moridani M.Y., Pourahmad J., Bui H., Siraki A., O’Brien P.J.: Free Radic. Biol. Med. 34, 243 (2003).

42. Ioku K., Tsushida T., Takei Y., Nakatani N., Terao J.: Biochim. Biophys. Acta 1234, 99 (1995).

43. Shi X., Niu L., Zhao L., Wang B., Jin Y., et al.: J. Food Process. Pres. 42, el3588 (2018).

44. Ginwala R., Bhavsar R., Chigbu D.I., Jain P., Khan Z.K.: Antioxidants (Basel) 8, 85 pages (2019).

45. Wang L., Song J., Liu A., Xiao B., Li S., et al.: Nat. Prod. Bioprospec. 10, 271 (2020).

46. Kopustinskiene D.M., Jakstas V., Savickas A., Bernatoniene J.: Nutrients 12, 79 pages (2020).

47. Vazhappilly C.G., Ansari S.A., Al-Jaleeli R., Al-Azawi A.M., Ramadan W.S., et al.: Inflammopharmacology 27, 863 (2019).

48. Maaliki D., Shaito A.A., Pintus G., El-Yazbi A., Eid A.H.: Curr. Opin. Pharmacol. 45, 57 (2019).

49. Imran M., Rauf A., Abu-Izneid T., Nadeem M., Shariati M.A., et al.: Biomed. Pharmacother. 1121, 108612 (2019).

50. Rodriguez-Mateos A., Vauzour D., Krueger C.G., Shanmuganayagam D., Reed J., et al.: Arch. Toxicol. 88, 1803 (2014).

51. Williamson G., Kay C., Crozier A.: Compr. Rev. Food Sci. Food Saf. 17, 1054 (2018).

52. Kumar Singh S., Patra A.: J. Integr. Med. 16, 273 (2018).

53. Ahmed S.I., Hayat M.Q., Tahir M., Mansoor Q., Ismail M., et al.: BMC Complement. Altern. Med. 16, 460 (2016).

54. Compaore M., Bakasso S., Meda R.N.T., Nacoulma O.G.: Medicines (Basel) 5, 22 pages (2018).

55. Halliwell B., Gutteridge J.M., Aruoma O.I.: Anal. Biochem. 165, 215 (1987).

56. Oyaizu M.: Jpn. J. Nutr. Diet. 44, 307 (1986). 
57. Dinis T.C., Maderia V.M., Almeida L.M.: Arch. Biochem. Biophys. 315, 161 (1994).

58. Majewska M., Czeczot H., Skrzycki M., Podsiad M.: Bromat. Chem. Toksykol. 44, 1 (2011) (in Polish).

59. Collin F.: Int. J. Mol. Sci. 20, 58 pages (2019).

60. Moalin M., Strijdonck G.P., Beckers M., Hagemen G., Borm P., et al.: Molecules 16, 9636 (2011).

61. Wright J.S., Johnson E.R., DiLabio G.A.: J. Am. Chem. Soc. 123, 1173 (2001).

62. Lesjak M., Srai S.K.S.: Pharmaceuticals (Basel) 12, 58 pages (2019).

63. Mira L., Fernandez M.T., Santos M., Rocha R., Florencio M.H., et al.: Free Radic. Res. 36, 1199 (2002).

64. Kejík Z., Kaplánek R., Masarik M., Babula P., Matkowski A., et al.: Int. J. Mol. Sci. 22, 646 (2021).
65. Firuzi O., Lacanna A., Petrucci R., Marrosu G., Saso L.: Biochim. Biophys. Acta 1721, 174 (2005).

66. Fernandez M.T., Mira M.L., Florencio M.H., Jennings K.R.: J. Inorg. Biochem. 92, 105 (2002).

67. Pulido R., Bravo L., Saura-Calixto F.: J. Agric. Food Chem. 48, 3396 (2000).

68. Galey J.-B.: Potential Use of Iron Chelators against Oxidative Damage, in Advances in Pharmacology, H. Sies, Ed. pp. 167-203, Academic Press 1996.

69. Kasprzak M.M., Erxleben A., Ochocki J.: RSC Advances 5, 45853 (2015).

70. Cheng I.F., Breen K.: Biometals 13, 77 (2000).

71. Morel I., Cillard P., Cillard J.: Flavonoid-metal interactions in biological systems, in Flavonoids in health and disease, C. Rice-Evans and L. Packer, Eds., pp. 163-176, Marcel Dekker. INC: New York 1998.

72. Hudson B.J.F., Lewis J.I.: Food Chem. 10, 47 (1983). 